\title{
Simulation of Electron Cloud Density Distributions in RHIC Dipoles at Injection and Transition and Estimates for Scrubbing Times
}

P. He, M. Blaskiewicz, W. Fischer

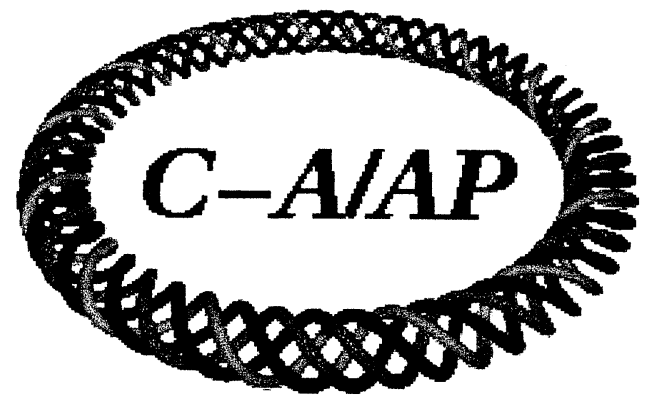

\section{Collider-Accelerator Department Brookhaven National Laboratory \\ Upton, NY 11973}

Notice: This document has been authorized by employees of Brookhaven Science Associates, LLC under Contract No. DE-AC02-98CH10886 with the U.S. Department of Energy. The United States Government retains a nonexclusive, paid-up, irrevocable, world-wide license to publish or reproduce the published form of this document, or allow others to do so, for United States Government purposes. 


\title{
SIMULATION OF ELECTRON CLOUD DENSITY DISTRIBUTIONS IN RHIC DIPOLES AT INJECTION AND TRANSITION AND ESTIMATES FOR SCRUBBING TIMES
}

\author{
P. He, M. Blaskiewicz and W. Fischer, BNL, Upton, NY11973, USA
}

\begin{abstract}
In this report we summarize electron-cloud simulations for the RHIC dipole regions at injection and transition to estimate if scrubbing over practical time scales at injection would reduce the electron cloud density at transition to significantly lower values. The lower electron cloud density at transition will allow for an increase in the ion intensity.
\end{abstract}

\section{INTRODUCTION}

Electron clouds are known to lower the instability threshold of ion bunches crossing the transition energy in RHIC [1-4]. At transition the bunches become short and their peak current increases while the synchrotron tune becomes small, making the bunches vulnerable to instabilities. At the same time, due to the bunch shortening, the beam-generated electron cloud density increases thereby reducing the instability threshold.

Throughout this paper we limit our investigation to the arc dipoles. Although the ring locations with high electron cloud density during transition crossing have not been established rigorously, the arc dipoles are a likely location. The beam pipes in the warm sections were largely replaced with NEG coated ones, which have a lower SEY than the bare stainless steel of the arc beam pipes. Furthermore, simulations and the SPS experience show an enhancement of the electron cloud density in regions with magnetic dipole fields compared to field free regions [5].

One possibility to increase the instability threshold is the reduction of the SEY through scrubbing which reduces the electron cloud density. Scrubbing had been proposed earlier [6] and was used already to a limited extend [6,7]. Scrubbing is routinely used in the SPS [5,8].

Scrubbing requires frequent refills of beams of the highest available intensities and can be done efficiently only at injection. The electron cloud distribution depends on the dipole field strength and the beam pipe locations scrubbed at injection may not necessarily yield a large improvement at transition. In this study we compare the horizontal electron cloud density distributions at injection and transition.

\section{ELECTRON CLOUD IN A DIPOLE FIELD}

In a normal dipole magnet, the electron motion is constrained to the vertical direction. Here, the electron receives only a net vertical kick from the passing bunches, while the net horizontal kick is approximately zero, due to the large number of cyclotron oscillations performed during the bunch passage [9]. During a bunch passage, an electron may either receive a single kick or perform a number of oscillations in the bunch potential, depending on its initial position. Electrons at large amplitudes do not move much during the bunch passage and simply receive a kick. Electrons near the bunch oscillate in the beam potential. In the dipole field, the electron cloud is neither concentrated around the beam nor spread out uniformly across the chamber. If the secondary emission yield is larger than the critical yield, the electron stripes occur in the region with maximum multipacting, and their position is sensitive to details of the secondary emission and the dipole field strength.

Table 1: Input parameters of e-cloud simulations for gold beam at injection and transition

\begin{tabular}{|c|c|c|c|}
\hline Parameter & Unit & Injection & Transition \\
\hline $\begin{array}{c}\text { Total ion } \\
\text { energy }\end{array}$ & GeV/nucleon & 9.795 & 24.675 \\
\hline Bunch spacing & $\mathrm{ns}$ & 108 & 108 \\
\hline $\begin{array}{c}\text { RMS bunch } \\
\text { length }\end{array}$ & $\mathrm{m}$ & $0.6 / 1.2$ & 0.5 \\
\hline $\begin{array}{c}\text { Number of } \\
\text { bunches }\end{array}$ & $\ldots$ & 110 & 110 \\
\hline $\begin{array}{c}\text { Bunch } \\
\text { intensity }\end{array}$ & $10^{9}$ & $1.0-1.5$ & $1.0-1.5$ \\
\hline Dipole field & $\mathrm{T}$ & 0.334 & 0.845 \\
\hline $\begin{array}{c}\text { Length of } \\
\text { dipole }\end{array}$ & $\mathrm{m}$ & 9.4 & 9.4 \\
\hline Peak SEY & $\ldots$ & $1.1-2.0$ & $1.1-2.0$ \\
\hline
\end{tabular}

\section{SIMULATION RESULTS}

We carried out our work by using the electron-cloud code POSINST[10]. The simulations have many input parameters and the result is sensitive to changes in a number of those parameters. We define cases for gold beams at injection and transition, with respect to the beam parameters. We are interested in the special structure of the electron-cloud, in particular the position of the vertical stripes, or regions of high electron density, which appear in the presence of a dipole magnetic field. The simulation input parameters are shown in Table 1.

In a first parameter scan we vary the SEY from 1.1 to 2.0 and observe the horizontal electron cloud density distribution at injection and transition. These are shown in Fig. 1 - Fig. 10 for the injection case with a bunch length 
of 1.2 m, Fig. 12 - Fig. 21 also for the injection case but with only half the bunch length as before, and in Fig. $35-$ Fig. 44 for transition. Half the bunch length could be achieved with proton beams after bunch rotation in the AGS and injected closed to the transition energy. With proton bunches the charge per bunch could be as high as $2 \times 10^{11} e$, larger than the charge per bunch quoted in Table 1 for gold beam. From these figures we conclude firstly that the surface locations that needed to be scrubbed to suppress the electron cloud at transition are scrubbed at injection, and secondly that for SEY between 1.4 and 1.6 half bunch length at injection is required to create electron cloud densities comparable to those created at transition.

Fig. 11, Fig. 22 and Fig. 34 show the average power deposited by the electron cloud on the chamber wall as a function of SEY at injection (full and half bunch length) and transition respectively. At transition, an SEY of 1.4 or lower reduces the energy deposition in the wall by 3 orders of magnitude from the values found with an SEY of 1.6 or higher. This is about the same at injection with half the bunch length, but not with the full bunch length. Scrubbing will therefore only be efficient if the bunch length can be reduced.

We now investigate by how much the bunch intensity at injection (with full bunch length) must exceed the desired intensity at transition in order to create the same electron cloud density. We choose two SEY values (1.4 and 1.5) close to the value where a large change in the electron cloud density has been observed in the first scan. With these two SEY values we vary the bunch intensity. Fig. 23 - Fig. 28 show the scan for $\mathrm{SEY}=1.4$ at injection, and Fig. $46-$ Fig. 51 at transition. Fig. $29-$ Fig. 34 and Fig. 52 - Fig. 57 show the bunch intensity scan for SEY = 1.5 at injection and transition respectively. For an SEY of 1.4 scrubbing with the highest available gold bunch intensity of $1.5 \times 10^{9}$ will allow bunch intensities of only $1.1 \times 10^{9}$ at transition. For an SEY of 1.5 scrubbing with $1.5 \times 10^{9}$ will allow bunch intensities of only $1.0 \times 10^{9}$ at transition. Gold bunch intensities of $1.0-1.1 \times 10^{9}$ have been reached already in operation $[3,4]$. We conclude again that scrubbing with gold bunches of full length at injection is not effective.

\section{SURFACE CONDITIONING WITH ELECTRONS}

In Table 5 we list the reported doses for conditioning the surface to a peak SEY of 1.3 or less. In the measurements the materials and electron energies vary. Our case of interest, stainless steel bombarded with $35 \mathrm{eV}$ electrons (see Tables 2-4), has not been measured directly but for all cases shown a dose of $D \approx 0.1 \mathrm{C} / \mathrm{cm}^{2}$ was needed to achieve a peak SEY of 1.3.

Ref. [13] reports that surface conditioning is observed for all electrons in the energy range from $20 \mathrm{eV}$ to $500 \mathrm{eV}$, with somewhat longer conditioning times needed for low energy electrons in the range $20-50 \mathrm{eV}$.
For comparison we note that a conditioning of the electron impact desorption coefficient $\eta_{\mathrm{e}}$ has been observed in RHIC for unbaked stainless steel surfaces. Over the course of a run $\eta_{\mathrm{e}}$ decreased from 0.05 to 0.02 [16]. No conditioning effect was observed for baked stainless steel.

Table 5. Reported doses for surface conditioning with electrons $(\mathrm{SS}=$ stainless steel, $\mathrm{NEG}=$ non-evaporable getter, IG = isotropic graphite).

\begin{tabular}{|l|c|c|l|}
\hline Materials & $\begin{array}{c}\text { Dose for peak } \\
\text { SEY=1.3 } \\
{\left[\mathrm{C} / \mathrm{cm}^{2}\right]}\end{array}$ & $\begin{array}{c}\text { Electron } \\
\text { energy } \\
{[\mathrm{eV}]}\end{array}$ & Comment \\
\hline $\begin{array}{l}\mathrm{Cu}, \mathrm{SS}, \mathrm{TiN}, \\
\mathrm{NEG}, \mathrm{IG}\end{array}$ & 0.16 & 5000 & $\begin{array}{l}\text { Ref. [11], } \\
\text { after air } \\
\text { exposure }\end{array}$ \\
\hline TiZrV/SS & 0.1 & 130 & Ref. [12] \\
\hline $\begin{array}{l}\text { TiZrV/Al, } \\
\text { TiN/Al, TiN/SS }\end{array}$ & 0.02 & 130 & Ref. [12] \\
\hline $\mathrm{Cu} / \mathrm{SS}$ & 0.1 & 500 & $\begin{array}{l}\text { Ref. [13], } \\
\text { initial peak } \\
\text { SEY=2.4 }\end{array}$ \\
\hline $\mathrm{Cu} / \mathrm{SS}$ & 0.1 & 100 & $\begin{array}{l}\text { Ref. [13], } \\
\text { initial peak } \\
\text { SEY =1.7 }\end{array}$ \\
\hline $\mathrm{Cu}$-co-laminated & 0.1 & $20-500$ & Ref. [14] \\
\hline
\end{tabular}

The time needed for conditioning can be estimated as

$$
t=\frac{D}{\left(\frac{P}{E} \frac{e}{S}\right)}
$$

Here $t$ is the time needed for the beam pipe scrubbing, $D$ is the electron dose needed to achieve the lower SEY (given in charge per area), $P$ is the power deposited into the surface area $S$ on the wall, $E$ is the average energy of the electron hitting the wall, and $e$ is the elementary charge. Using Eq. (1), we can estimate the RHIC scrubbing time at injection for full $(1.2 \mathrm{~m})$ and half $(0.6 \mathrm{~m})$ bunch length for various values of SEY, a dose of $0.1 \mathrm{C} / \mathrm{cm}^{2}$, an electron energy of $35 \mathrm{eV}$, and a surface area of $400 \mathrm{~cm}^{2}$. The results are shown in Table 6 . Note that during the scrubbing the SEY becomes smaller. Scrubbing times with an SEY of 1.4 even at half bunch length are many days and are not practical. We conclude from Table 6 that scrubbing at injection with half the normal bunch length over a few days may be sufficient to bring the SEY to a value below 1.5, which in turn should allow acceleration of gold bunches with an intensity of more than $1.2 \times 10^{9}$ through transition.

\begin{tabular}{|c|c|c|}
\hline SEY & $\begin{array}{c}\text { full bunch length } \\
(1.2 \mathrm{~m})\end{array}$ & $\begin{array}{c}\text { half bunch length } \\
(0.6 \mathrm{~m})\end{array}$ \\
\hline 1.8 & 3 hours & 2 hours \\
\hline 1.6 & 50 hours & 4 hours \\
\hline 1.5 & 300 days & 20 hours \\
\hline
\end{tabular}

Table 6. Estimated scrubbing times for RHIC. 


\section{SUMMARY}

We simulated the transverse distribution of the electron clouds in the RHIC dipole chamber at injection and transition with gold beams. At transition the power deposited into the wall is reduced by more than 2 orders of magnitude when the SEY is reduced from 1.5 to 1.4. Thus, an SEY of 1.4 or less should significantly increase the intensity instability threshold at transition.

To achieve an SEY of 1.4 at transition, the beam pipe surface can be scrubbed with electrons from an electron cloud at injection. From the simulations we expect scrubbing with gold bunches of normal length to be inefficient. Scrubbing with bunches of half length, however, is efficient. The beam pipe areas bombarded by electron clouds at injection and transition are sufficiently close, and we estimate a scrubbing time of a few days to bring the SEY to values smaller than 1.5. To achieve short bunches scrubbing can be done with protons that are bunch rotated in the AGS and injected close to the transition energy [11]. Proton bunches can also have charges about twice as large as ion bunches which would further enhance the scrubbing efficiency.

\section{ACKNOWLEDGEMENTS}

We are thankful for discussions to G. Arduini (CERN), R. De Maria, M. Jimenez (CERN), and G. Rumolo (CERN). We thank X. Zhang (FNAL) for help with the installation of a new version of the POSINST code at BNL.

\section{REFERENCES}

[1] C. Montag et al., Phys. Rev. ST - Accel. Beams 5, 084401 (2002).

[2] M. Blaskiewicz et al., proceedings PAC'03, pp. 30263028 (2003).
[3] W. Fischer et al., proceedings EPAC'08, pp. 16161618 (2008)

[4] V. Ptitsyn et al., proceedings HB 2008, to be published.

[5] J.M. Jimenez, proceedings PAC'03, pp. 307-311 (2003)

[6] S.Y. Zhang et al., proceedings EPAC'04, pp. 947-949 (2004).

[7] W. Fischer et al., Phys. Rev. ST - Accel. Beams 11, 041002 (2008).

[8] G. Arduini et al., proceedings ECLOUD'04, $31^{\text {st }}$ Advanced ICFA Beam Dynamics Workshop on Electron Cloud Effects, Napa, CA, Report No. CERN-2005-0001, CARE-Conf-05-001-HHH, LBNL-56372, SNS-1034000000-TR0024-R00, pp. 31-47 (2005).

[9] F. Zimmermann, proceedings XII Chamonix Workshop (2002).

[10] M.A. Furman and M.T.F. Pivi, Phys. Rev. ST Accel. Beams 5, 124404 (2003).

[11] M. Nishiwaki and S. Kato, proceedings ECLOUD'07, KEK Proceedings 2007-10, pp. 82-85 (2007).

[12] F. Le Pimpec, R.E. Kirby, F.K. King, and M. Pivi, proceedings ECLOUD'07, KEK Proceedings 200710, pp. 68-71 (2007).

[13] N. Hilleret et al., proceedings PAC'99, pp. 26292631 (1999).

[14] R. Cimino et al., proceedings EPAC'08, pp. 15921594 (2008).

[15] U. Iriso and W. Fischer, Phys. Rev. ST - Accel. Beams 8, 113201 (2005). 


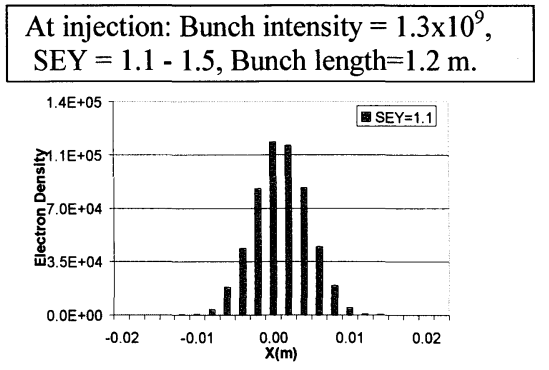

Figure 1. Electron cloud distribution in RHIC dipole field for $\mathrm{B}=0.334 \mathrm{~T}$ and $\mathrm{SEY}=1.1$, bunch length $=1.2 \mathrm{~m}$.

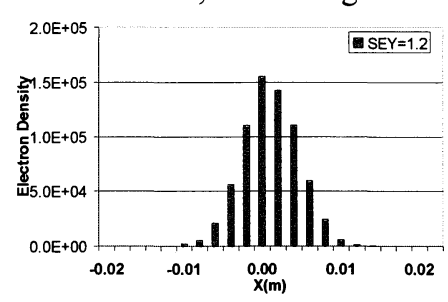

Figure 2. Electron cloud distribution in RHIC dipole field for $\mathrm{B}=0.334 \mathrm{~T}$ and $S E Y=1.2$, bunch length $=1.2 \mathrm{~m}$.

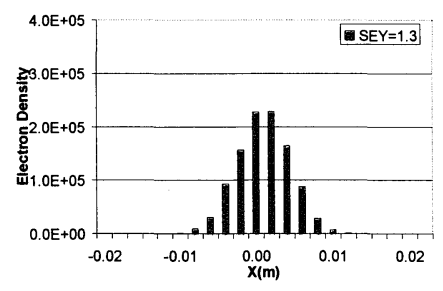

Figure 3. Electron cloud distribution in RHIC dipole field for $\mathrm{B}=0.334 \mathrm{~T}$ and $\mathrm{SEY}=1.3$, bunch length $=1.2 \mathrm{~m}$.

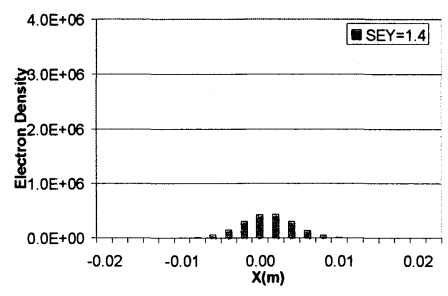

Figure 4. Electron cloud distribution in RHIC dipole field for $\mathrm{B}=0.334 \mathrm{~T}$ and $\mathrm{SEY}=1.4$, bunch length $=1.2 \mathrm{~m}$.

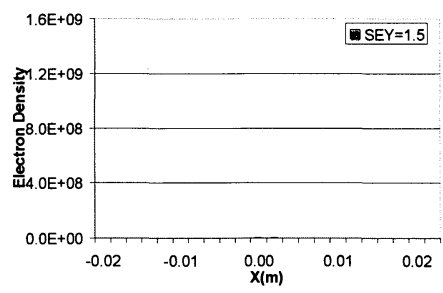

Figure 5. Electron cloud distribution in RHIC dipole field for $\mathrm{B}=0.334 \mathrm{~T}$ and $\mathrm{SEY}=1.5$, bunch length $=1.2 \mathrm{~m}$.
At injection: Bunch intensity $=1.3 \times 10^{9}$,

$\mathrm{SEY}=1.1-1.5$, Bunch length $=0.6 \mathrm{~m}$.

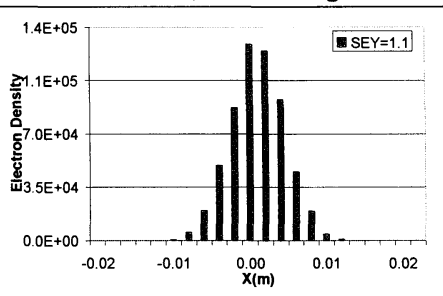

Figure 12. Electron cloud distribution in RHIC dipole field for $\mathrm{B}=0.334 \mathrm{~T}$ and $\mathrm{SEY}=1.1$, bunch length $=0.6 \mathrm{~m}$.

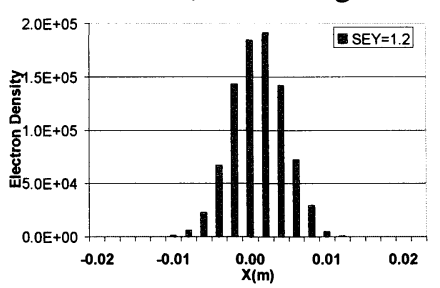

Figure 13. Electron cloud distribution in RHIC dipole field for $\mathrm{B}=0.334 \mathrm{~T}$ and $\mathrm{SEY}=1.2$, bunch length $=0.6 \mathrm{~m}$.

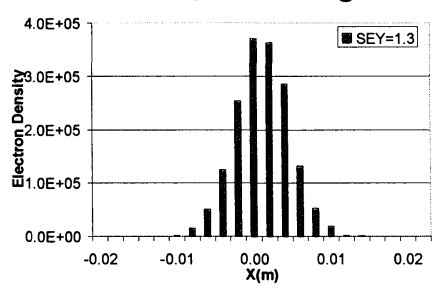

Figure 14. Electron cloud distribution in RHIC dipole field for $\mathrm{B}=0.334 \mathrm{~T}$ and $\mathrm{SEY}=1.3$, bunch length $=0.6 \mathrm{~m}$.

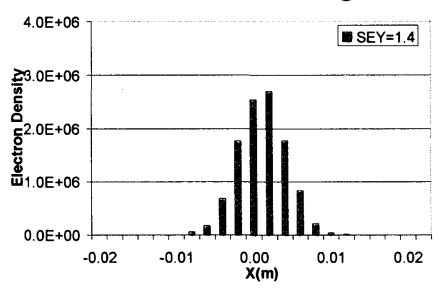

Figure 15. Electron cloud distribution in RHIC dipole field for $\mathrm{B}=0.334 \mathrm{~T}$ and $\mathrm{SEY}=1.4$, bunch length $=0.6 \mathrm{~m}$.

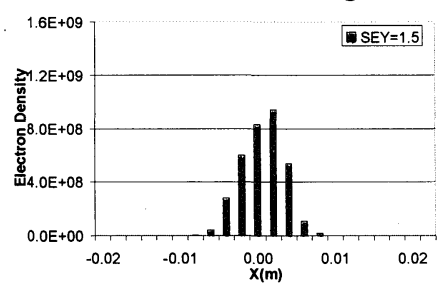

Figure 16. Electron cloud distribution in RHIC dipole field for $\mathrm{B}=0.334 \mathrm{~T}$ and $\mathrm{SEY}=1.5$, bunch length $=0.6 \mathrm{~m}$.

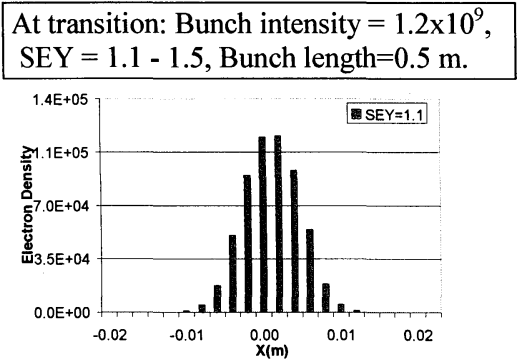

Figure 35. Electron cloud distribution in RHIC dipole field for $\mathrm{B}=0.845 \mathrm{~T}$ and $\mathrm{SEY}=1.1$, bunch length $=0.5 \mathrm{~m}$.

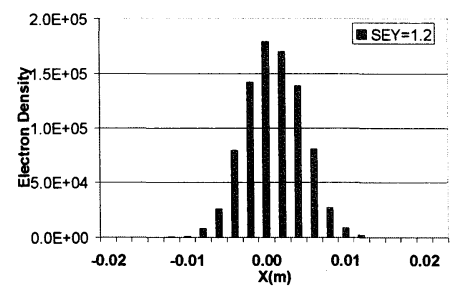

Figure 36. Electron cloud distribution in RHIC dipole field for $\mathrm{B}=0.845 \mathrm{~T}$ and $\mathrm{SEY}=1.2$, bunch length $=0.5 \mathrm{~m}$.

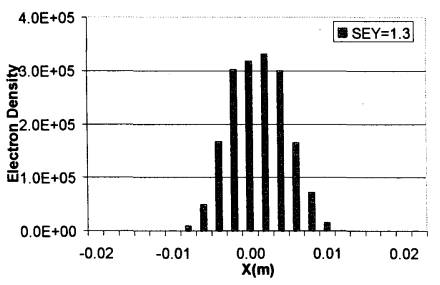

Figure 37. Electron cloud distribution in RHIC dipole field for $\mathrm{B}=0.845 \mathrm{~T}$ and $\mathrm{SEY}=1.3$, bunch length $=0.5 \mathrm{~m}$.

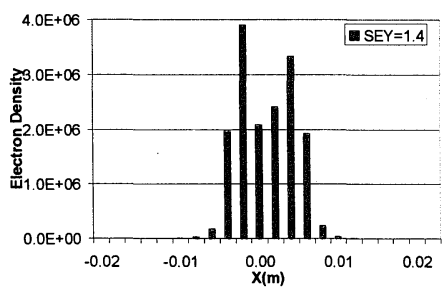

Figure 38. Electron cloud distribution in RHIC dipole field for $\mathrm{B}=0.845 \mathrm{~T}$ and $S E Y=1.4$, bunch length $=0.5 \mathrm{~m}$.

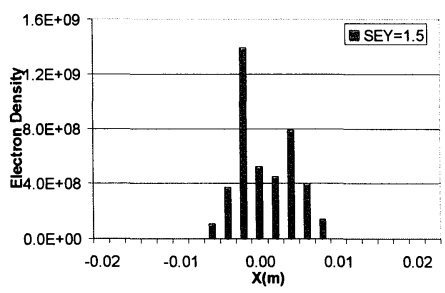

Figure 39. Electron cloud distribution in RHIC dipole field for $\mathrm{B}=0.845 \mathrm{~T}$ and $\mathrm{SEY}=1.5$, bunch length $=0.5 \mathrm{~m}$. 


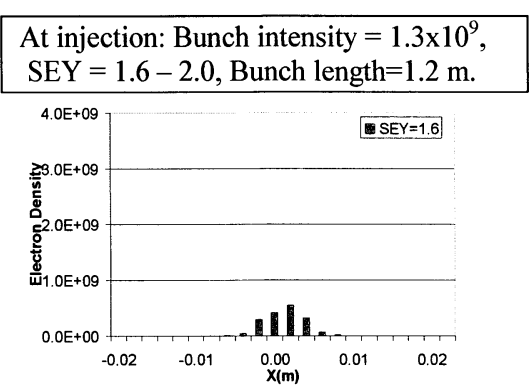

Figure 1. Electron cloud distribution in RHIC dipole field for $\mathrm{B}=0.334 \mathrm{~T}$ and $\mathrm{SEY}=1.6$, bunch length $=1.2 \mathrm{~m}$.

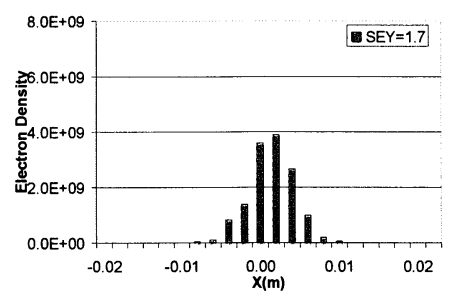

Figure 2. Electron cloud distribution in RHIC dipole field for $\mathrm{B}=0.334 \mathrm{~T}$ and $\mathrm{SEY}=1.7$, bunch length $=1.2 \mathrm{~m}$.

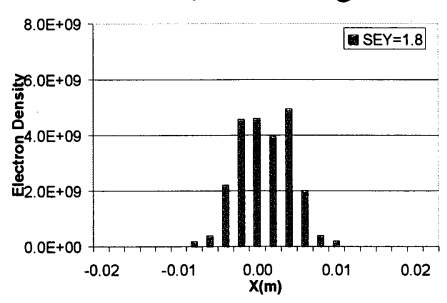

Figure 3. Electron cloud distribution in RHIC dipole field for $\mathrm{B}=0.334 \mathrm{~T}$ and $\mathrm{SEY}=1.8$, bunch length $=1.2 \mathrm{~m}$.

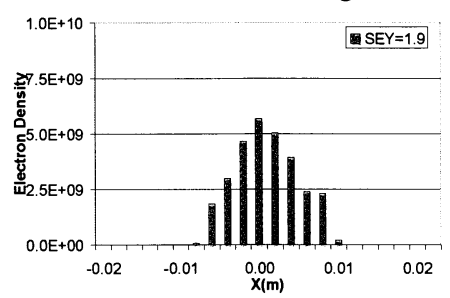

Figure 4. Electron cloud distribution in RHIC dipole field for $\mathrm{B}=0.334 \mathrm{~T}$ and $\mathrm{SEY}=1.9$, bunch length $=1.2 \mathrm{~m}$.

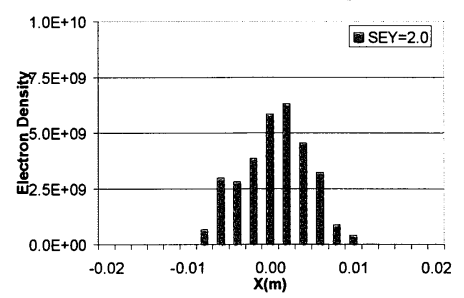

Figure 5. Electron cloud distribution in RHIC dipole field for $\mathrm{B}=0.334 \mathrm{~T}$ and SEY $=2.0$, bunch length $=1.2 \mathrm{~m}$.
At injection: Bunch intensity $=1.3 \times 10^{9}$, $\mathrm{SEY}=1.6-2.0$, Bunch length $=0.6 \mathrm{~m}$.

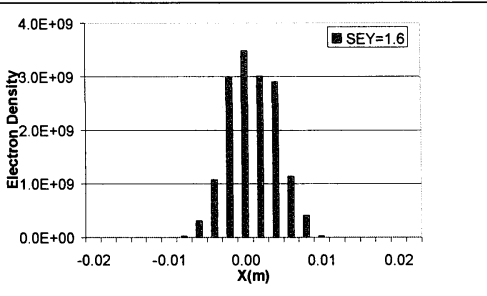

Figure 17. Electron cloud distribution in RHIC dipole field for $\mathrm{B}=0.334 \mathrm{~T}$ and $\mathrm{SEY}=1.6$, bunch length $=0.6 \mathrm{~m}$.

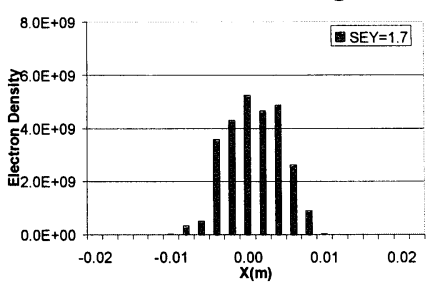

Figure 18. Electron cloud distribution in RHIC dipole field for $\mathrm{B}=0.334 \mathrm{~T}$ and $\mathrm{SEY}=1.7$, bunch length $=0.6 \mathrm{~m}$.

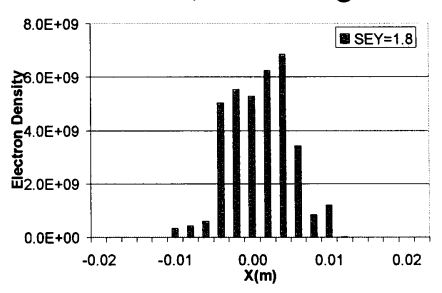

Figure 19. Electron cloud distribution in RHIC dipole field for $\mathrm{B}=0.334 \mathrm{~T}$ and $\mathrm{SEY}=1.8$, bunch length $=0.6 \mathrm{~m}$.

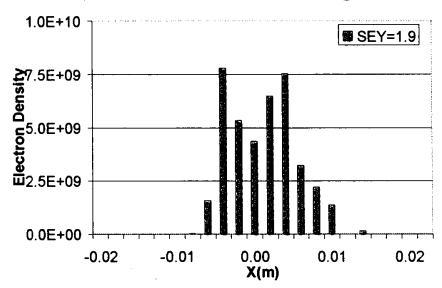

Figure 20. Electron cloud distribution in RHIC dipole field for $\mathrm{B}=0.334 \mathrm{~T}$ and $\mathrm{SEY}=1.9$, bunch length $=0.6 \mathrm{~m}$.

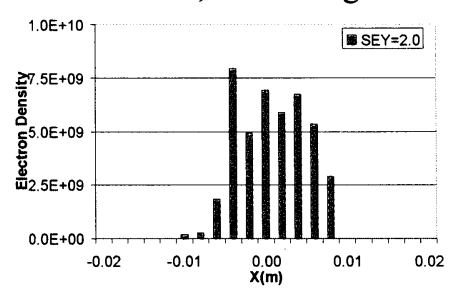

Figure 21. Electron cloud distribution in RHIC dipole field for $\mathrm{B}=0.334 \mathrm{~T}$ and $\mathrm{SEY}=2.0$, bunch length $=0.6 \mathrm{~m}$.

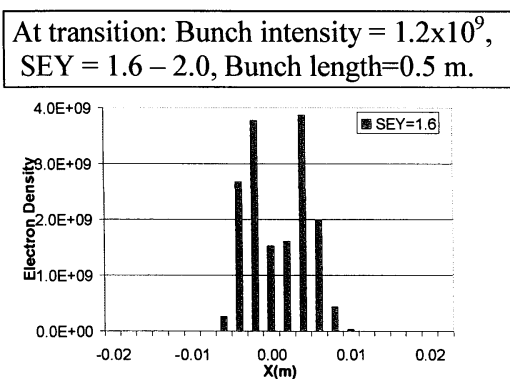

Figure 40. Electron cloud distribution in RHIC dipole field for $\mathrm{B}=0.845 \mathrm{~T}$ and $\mathrm{SEY}=1.6$, bunch length $=0.5 \mathrm{~m}$.

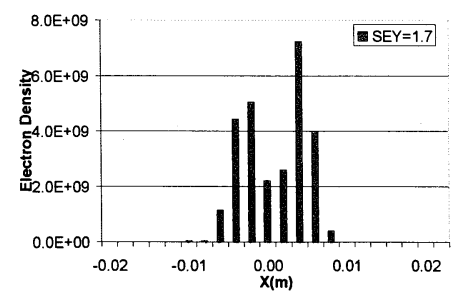

Figure 41. Electron cloud distribution in RHIC dipole field for $\mathrm{B}=0.845 \mathrm{~T}$ and $\mathrm{SEY}=1.7$, bunch length $=0.5 \mathrm{~m}$.

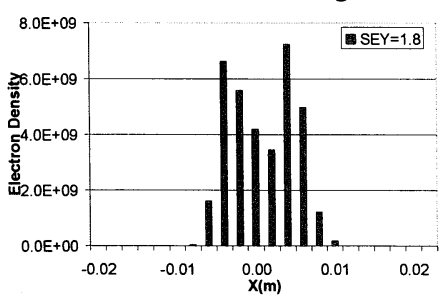

Figure 42. Electron cloud distribution in RHIC dipole field for $\mathrm{B}=0.845 \mathrm{~T}$ and $\mathrm{SEY}=1.8$, bunch length $=0.5 \mathrm{~m}$.

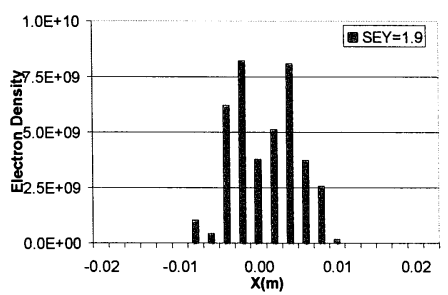

Figure 43. Electron cloud distribution in RHIC dipole field for $\mathrm{B}=0.845 \mathrm{~T}$ and $S E Y=1.9$, bunch length $=0.5 \mathrm{~m}$.

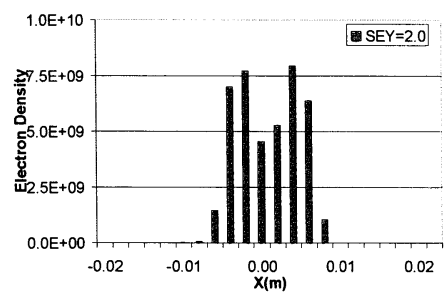

Figure 44. Electron cloud distribution in RHIC dipole field for $\mathrm{B}=0.845 \mathrm{~T}$ and $\mathrm{SEY}=2.0$, bunch length $=0.5 \mathrm{~m}$. 


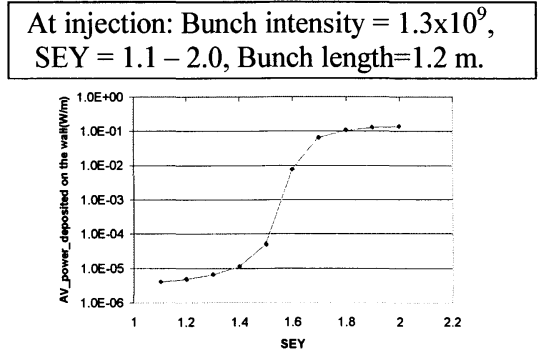

Figure 11. Electron cloud average power deposited on the chamber wall vs SEY at injection, bunch length = $1.2 \mathrm{~m}$.

\begin{tabular}{|c|c|}
\hline SEY & $\begin{array}{c}\text { Average energy } \\
\text { of electrons } \\
\text { hitting the wall } \\
(\mathrm{eV})\end{array}$ \\
\hline 1.1 & 40.6 \\
\hline 1.2 & 39.1 \\
\hline 1.3 & 37.3 \\
\hline 1.4 & 35.7 \\
\hline 1.5 & 34.2 \\
\hline 1.6 & 34.2 \\
\hline 1.7 & 33.9 \\
\hline 1.8 & 31.9 \\
\hline 1.9 & 31.6 \\
\hline 2.0 & 32.1 \\
\hline
\end{tabular}

Table 2. Average energy of the electrons hitting the wall vs SEY at injection, bunch length $=1.2 \mathrm{~m}$.
At injection: Bunch intensity $=1.3 \times 10^{9}$,

$\mathrm{SEY}=1.1-2.0$, Bunch length $=0.6 \mathrm{~m}$.

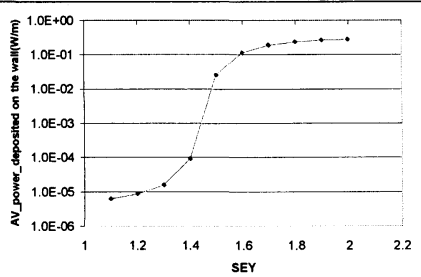

Figure 22. Electron cloud average power deposited on the chamber wall vs SEY at injection, bunch length = $0.6 \mathrm{~m}$.

\begin{tabular}{|c|c|}
\hline SEY & $\begin{array}{c}\text { Average energy } \\
\text { of electrons } \\
\text { hitting the wall } \\
(\mathrm{eV})\end{array}$ \\
\hline 1.1 & 41.8 \\
\hline 1.2 & 40.7 \\
\hline 1.3 & 39.3 \\
\hline 1.4 & 38.7 \\
\hline 1.5 & 38.5 \\
\hline 1.6 & 37.4 \\
\hline 1.7 & 36.3 \\
\hline 1.8 & 35.7 \\
\hline 1.9 & 35.8 \\
\hline 2.0 & 36.5 \\
\hline
\end{tabular}

Table 3. Average energy of the electrons hitting the wall vs SEY at injection, bunch length $=0.6 \mathrm{~m}$.
At transition: Bunch intensity $=1.2 \times 10^{9}$, $\mathrm{SEY}=1.1-2.0$, Bunch length $=0.5 \mathrm{~m}$.

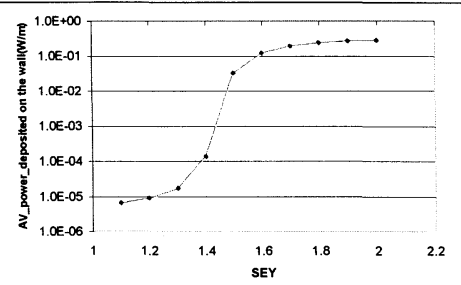

Figure 45. Electron cloud average power deposited on the wall vs SEY at transition in the RHIC dipole chamber.

\begin{tabular}{|c|c|}
\hline SEY & $\begin{array}{c}\text { Average energy } \\
\text { of electrons } \\
\text { hitting the wall } \\
(\mathrm{eV})\end{array}$ \\
\hline 1.1 & 43.1 \\
\hline 1.2 & 41.3 \\
\hline 1.3 & 39.8 \\
\hline 1.4 & 39.2 \\
\hline 1.5 & 38.6 \\
\hline 1.6 & 37.4 \\
\hline 1.7 & 36.6 \\
\hline 1.8 & 35.9 \\
\hline 1.9 & 36.0 \\
\hline 2.0 & 37.2 \\
\hline
\end{tabular}

Table 4. Average energy of the electrons hitting the wall vs SEY at transition. 


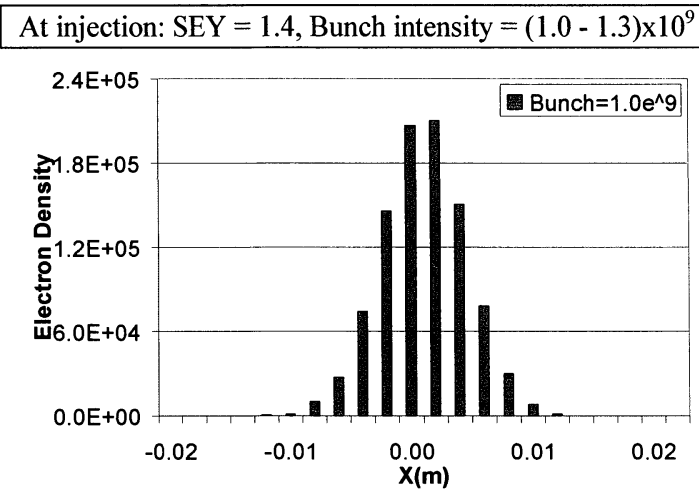

Figure 23. EC distribution in RHIC dipole field for $\mathrm{B}=$ $0.334 \mathrm{~T}$ and $\mathrm{SEY}=1.4$, bunch intensity $=1.0 \times 10^{9}$.

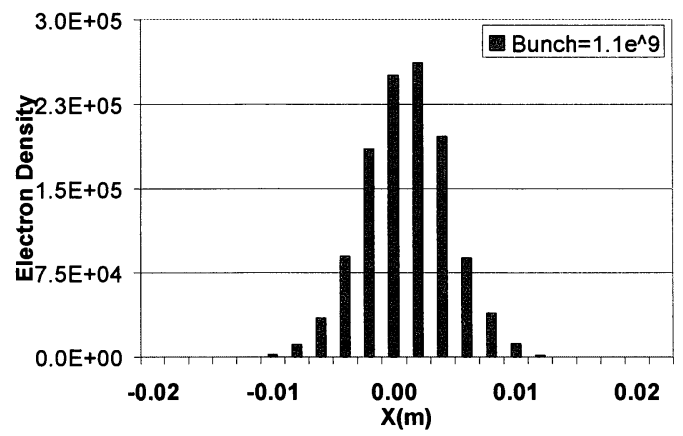

Figure 24. EC distribution in RHIC dipole field for $\mathrm{B}=$ $0.334 \mathrm{~T}$ and $\mathrm{SEY}=1.4$, bunch intensity $=1.1 \times 10^{9}$.

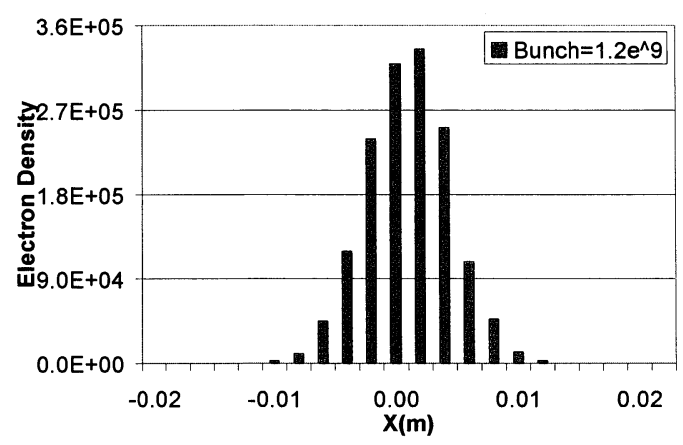

Figure 25. EC distribution in RHIC dipole field for $\mathrm{B}=$ $0.334 \mathrm{~T}$ and $\mathrm{SEY}=1.4$, bunch intensity $=1.2 \times 10^{9}$.

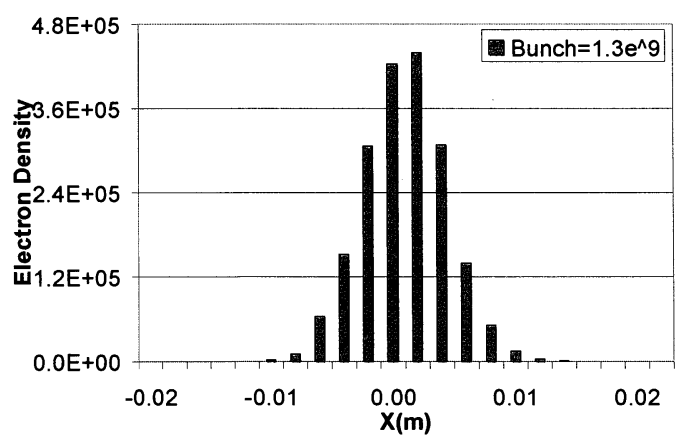

Figure 26. EC distribution in RHIC dipole field for $\mathrm{B}=$ $0.334 \mathrm{~T}$ and $\mathrm{SEY}=1.4$, bunch intensity $=1.3 \times 10^{9}$.

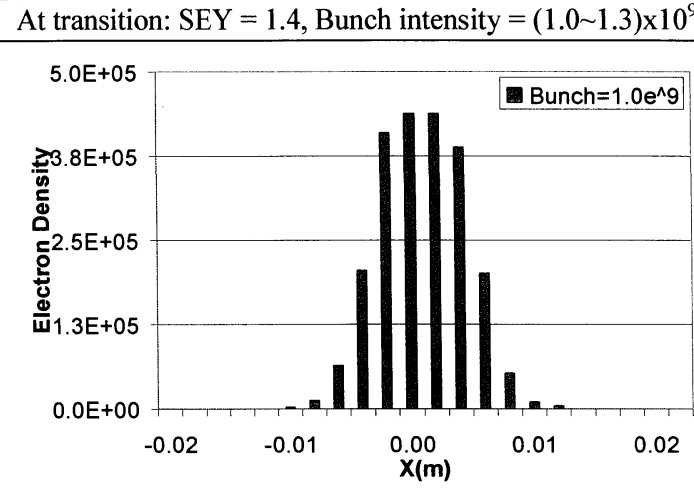

Figure 46. EC distribution in RHIC dipole field for $\mathrm{B}=$ $0.845 \mathrm{~T}$ and $\mathrm{SEY}=1.4$, bunch intensity $=1.0 \times 10^{9}$.

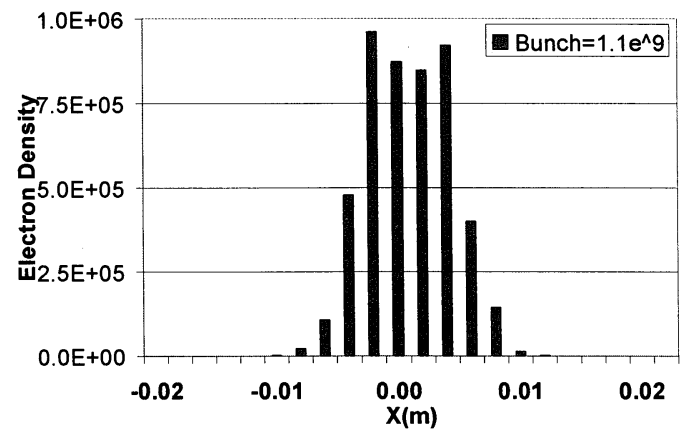

Figure 47. EC distribution in RHIC dipole field for $\mathrm{B}=$ $0.845 \mathrm{~T}$ and $\mathrm{SEY}=1.4$, bunch intensity $=1.1 \times 10^{9}$.

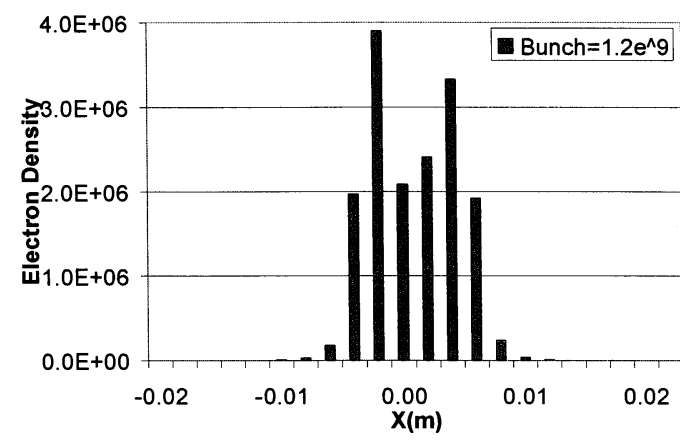

Figure 48. EC distribution in RHIC dipole field for $\mathrm{B}=$ $0.845 \mathrm{~T}$ and $\mathrm{SEY}=1.4$, bunch intensity $=1.2 \times 10^{9}$.

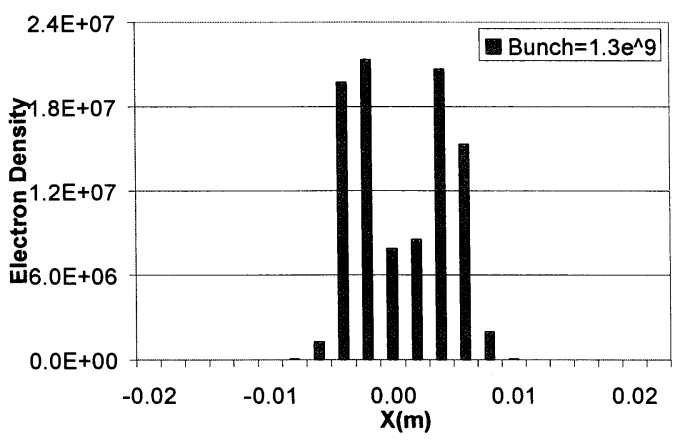

Figure 49. EC distribution in RHIC dipole field for $\mathrm{B}=$ $0.845 \mathrm{~T}$ and $\mathrm{SEY}=1.4$, bunch intensity $=1.3 \times 10^{9}$. 

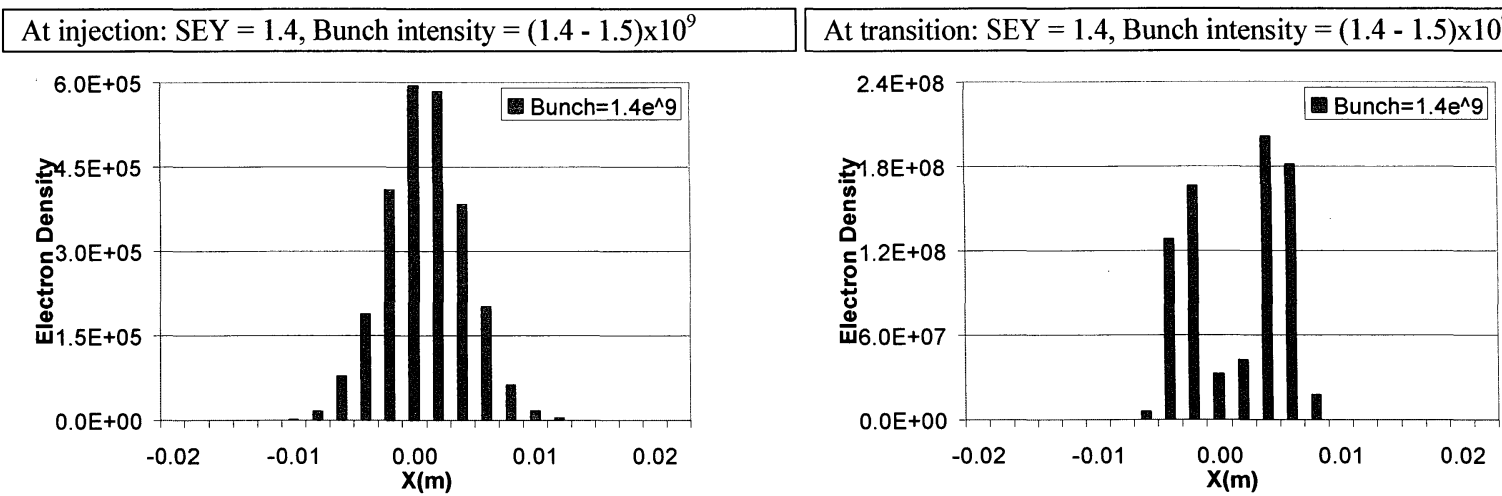

Figure 27. EC distribution in RHIC dipole field for $\mathrm{B}=$ $0.334 \mathrm{~T}$ and $\mathrm{SEY}=1.4$, bunch intensity $=1.4 \times 10^{9}$.

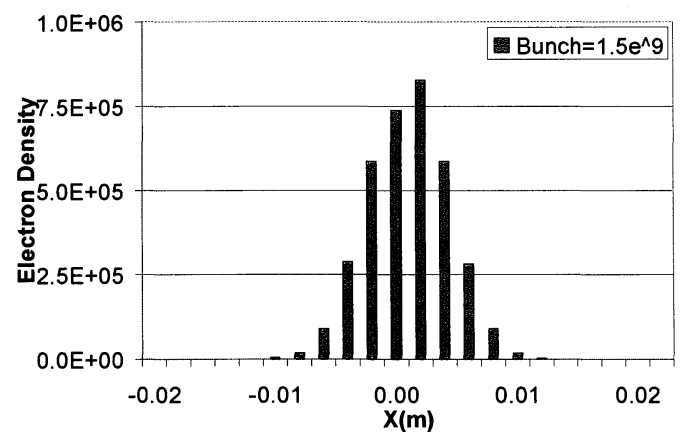

Figure 50. EC distribution in RHIC dipole field for $\mathrm{B}=$ $0.845 \mathrm{~T}$ and $\mathrm{SEY}=1.4$, bunch intensity $=1.4 \times 10^{9}$.

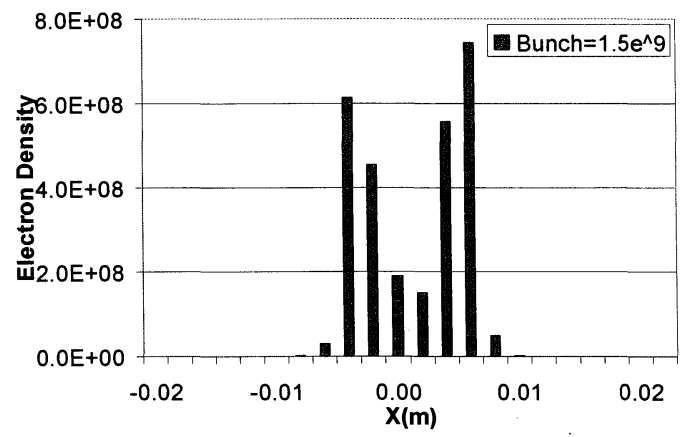

Figure 28. EC distribution in RHIC dipole field for $\mathrm{B}=$ $0.334 \mathrm{~T}$ and $\mathrm{SEY}=1.4$, bunch intensity $=1.5 \times 10^{9}$.

Figure 51. EC distribution in RHIC dipole field for $\mathrm{B}=$ $0.845 \mathrm{~T}$ and $\mathrm{SEY}=1.4$, bunch intensity $=1.5 \times 10^{9}$. 


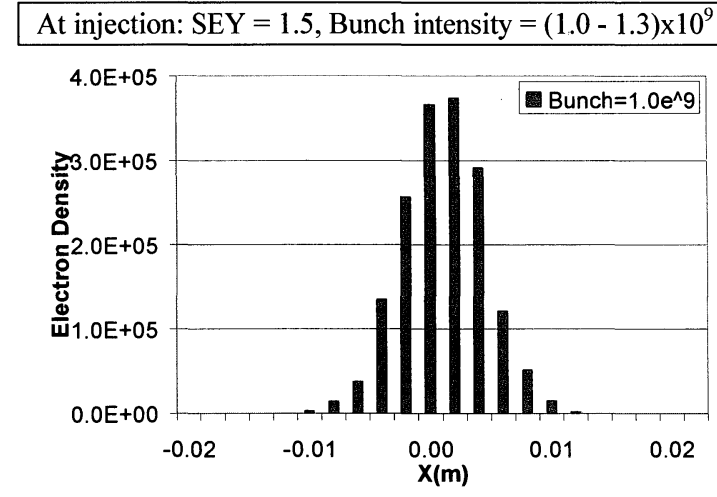

Figure 29. EC distribution in RHIC dipole field for $\mathrm{B}=$ $0.334 \mathrm{~T}$ and $\mathrm{SEY}=1.5$, bunch intensity $=1.0 \times 10^{9}$.

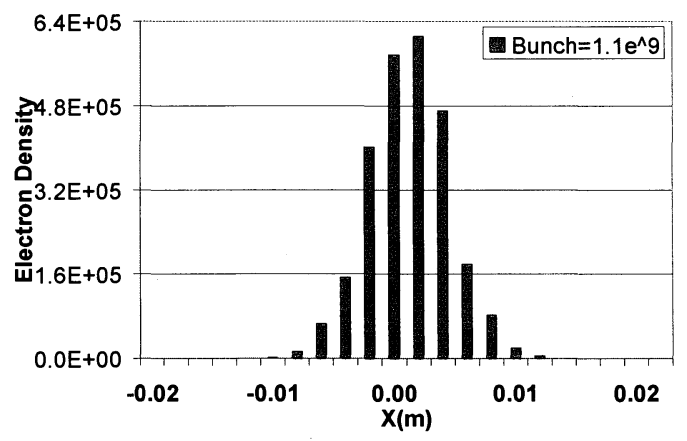

Figure 30. EC distribution in RHIC dipole field for $\mathrm{B}=$ $0.334 \mathrm{~T}$ and $\mathrm{SEY}=1.5$, bunch intensity $=1.1 \times 10^{9}$.

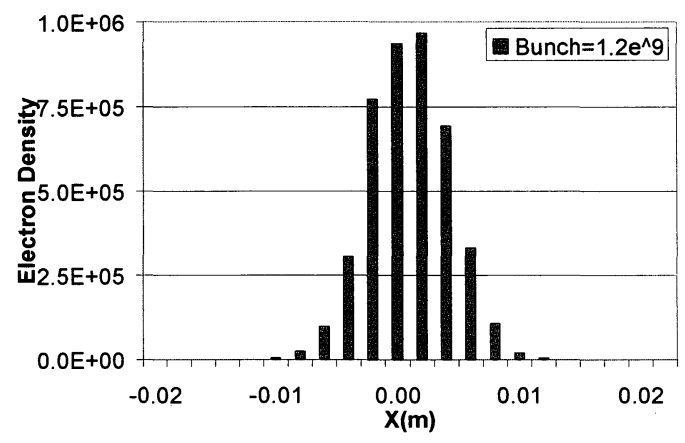

Figure 31. EC distribution in RHIC dipole field for $\mathrm{B}=$ $0.334 \mathrm{~T}$ and $\mathrm{SEY}=1.5$, bunch intensity $=1.2 \times 10^{9}$.

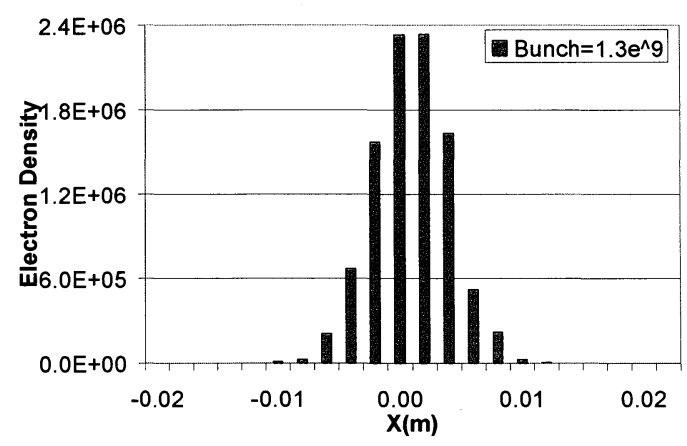

Figure 32. EC distribution in RHIC dipole field for $\mathrm{B}=$ $0.334 \mathrm{~T}$ and $\mathrm{SEY}=1.5$, bunch intensity $=1.3 \times 10^{9}$.

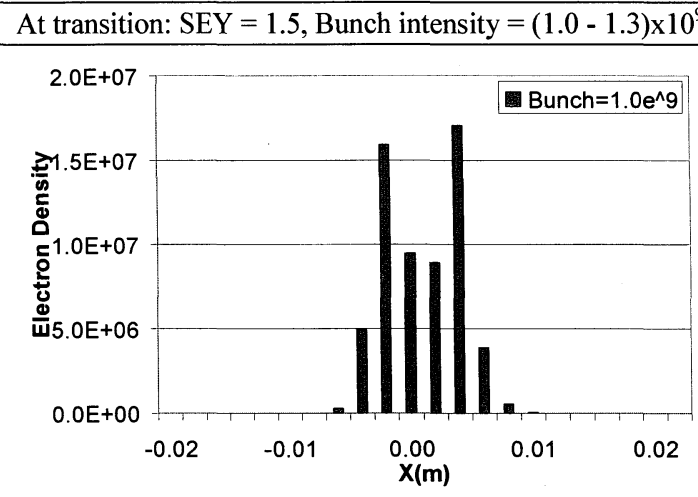

Figure 52. EC distribution in RHIC dipole field for $\mathrm{B}=$ $0.845 \mathrm{~T}$ and $\mathrm{SEY}=1.5$, bunch intensity $=1.0 \times 10^{9}$.

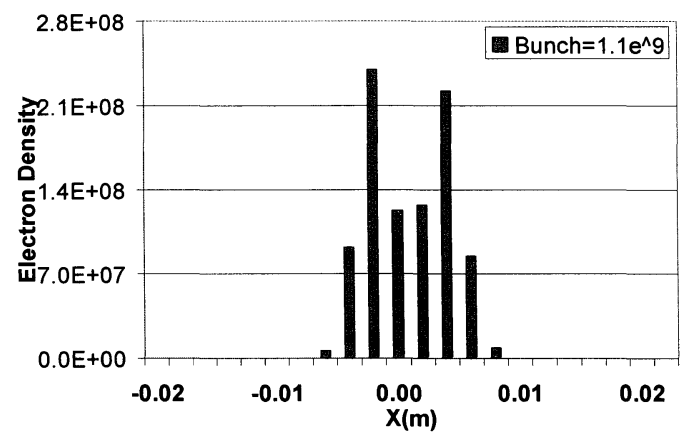

Figure 53. EC distribution in RHIC dipole field for $\mathrm{B}=$ $0.845 \mathrm{~T}$ and $\mathrm{SEY}=1.5$, bunch intensity $=1.1 \times 10^{9}$.

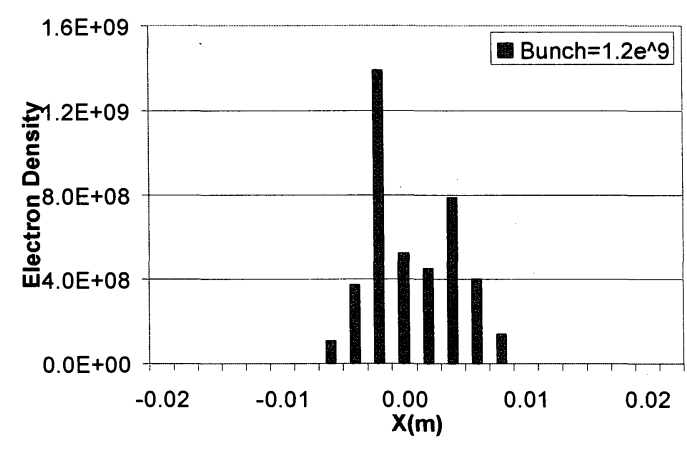

Figure 54. EC distribution in RHIC dipole field for $\mathrm{B}=$ $0.845 \mathrm{~T}$ and $\mathrm{SEY}=1.5$, bunch intensity $=1.2 \times 10^{9}$.

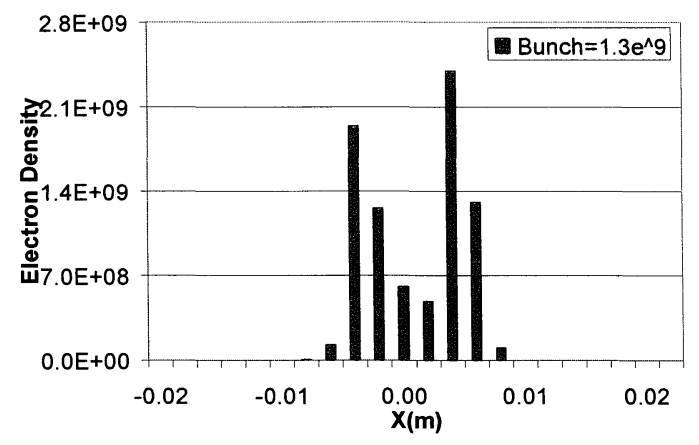

Figure 55. EC distribution in RHIC dipole field for $\mathrm{B}=$ $0.845 \mathrm{~T}$ and $\mathrm{SEY}=1.5$, bunch intensity $=1.3 \times 10^{9}$. 


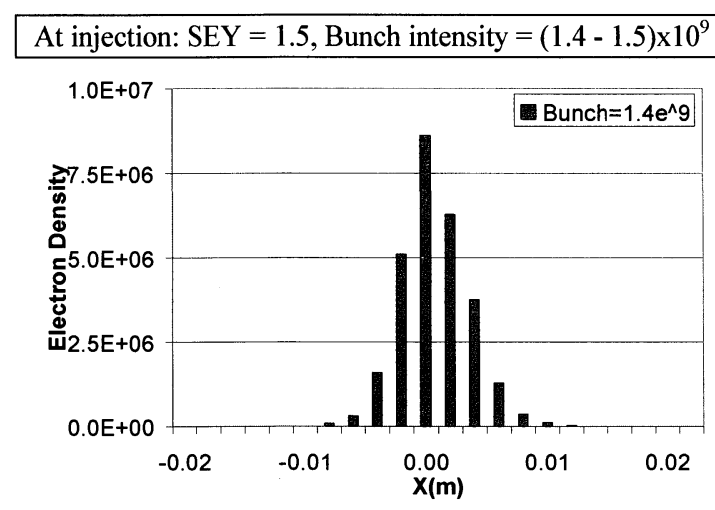

Figure 33. EC distribution in RHIC dipole field for $\mathrm{B}=$ $0.334 \mathrm{~T}$ and $\mathrm{SEY}=1.5$, bunch intensity $=1.4 \times 10^{9}$.

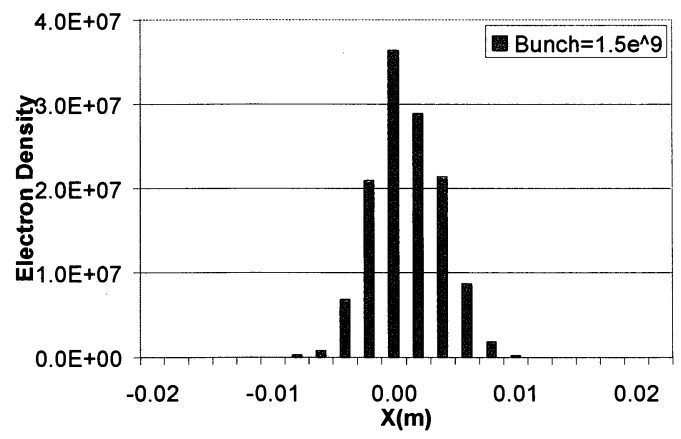

Figure 34. EC distribution in RHIC dipole field for $\mathrm{B}=$ $0.334 \mathrm{~T}$ and $\mathrm{SEY}=1.5$, bunch intensity $=1.5 \times 10^{9}$.
At transition: $\mathrm{SEY}=1.5$, Bunch intensity $=(1.4-1.5) \times 10^{9}$

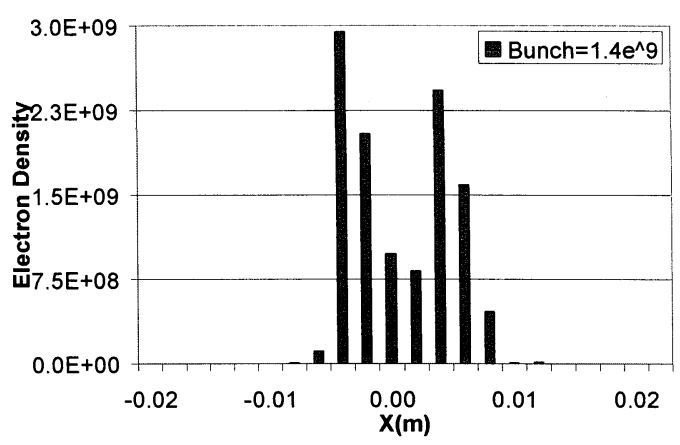

Figure 56. EC distribution in RHIC dipole field for $\mathrm{B}=$ $0.845 \mathrm{~T}$ and $\mathrm{SEY}=1.5$, bunch intensity $=1.4 \times 10^{9}$.

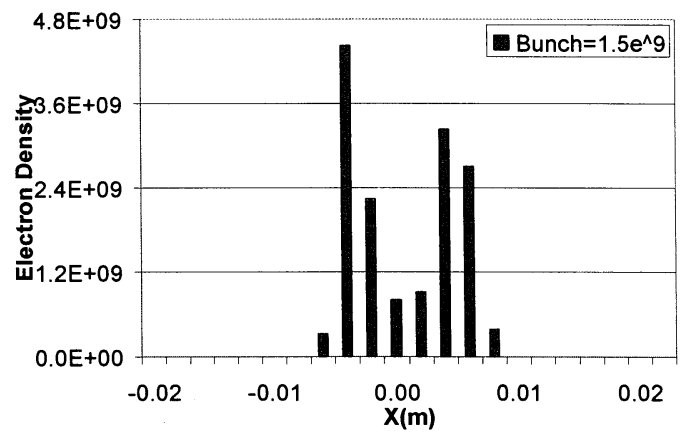

Figure 57. $\mathrm{EC}$ distribution in RHIC dipole field for $\mathrm{B}=$ $0.845 \mathrm{~T}$ and $\mathrm{SEY}=1.5$, bunch intensity $=1.5 \times 10^{9}$. 